\title{
APONTAMENTOS SOBRE A GEOPOLÍTICA DAS MÍDIAS
}

NOTES ON THE GEOPOLITICS OF MEDIA

NOTAS SOBRE LA GEOPOLÍTICA DE LOS MÉDIOS

JANAINA VISIBELI BARROS 1

\section{GILSON RASLAN²}

${ }^{1}$ Doutora em Ciências da Comunicação pela Universidade de São Paulo (USP). Docente da Universidade do Estado de Minas Gerais (UEMG) nos cursos de Jornalismo e Comunicação Social. Membro do Grupo de Estudos e Pesquisas das Poéticas do Cotidiano (EPCO). ORCID iD: https://orcid.org/0000-0003-4373-4103

${ }^{2}$ Doutor em Comunicação e Cultura pela Universidade de São Paulo (USP). Docente da Universidade do Estado de Minas Gerais (UEMG) nos cursos de Jornalismo e Comunicação Social. Coordena o Grupo de Estudos e Pesquisas das Poéticas do Cotidiano (EPCO). ORCID iD: https://orcid.org/0000-0002-2428-7240

\section{RESUMO}

Na mundialização do capital, os oligopólios de comunicação assumem papel relevante como agentes discursivos e econômicos, utilizando de suas redes de comunicação e recursos de transmissão de dados. Os bens culturais que a mídia oligopolizada produz transitam, atravessam os territórios, participando da formação de consensos sob a lógica contemporânea da acumulação flexível e da manutenção do status quo. Por se tratar de uma articulação espacial de poderes simbólicos, econômicos e políticos (WEBER, 1999), este artigo se interessa em discutir a geopolítica das mídias, a partir dos postulados desenvolvidos pelo geógrafo Philippe Boulanger (2014). A interface entre geopolítica das mídias e a comunicação contribui para pesquisas sobre disputas de poder entre agentes nos territórios.

Palavras-chave: Comunicação. Geopolítica. Mídia. Poder. 


\begin{abstract}
In the globalization of capital, communication oligopolies assume a relevant role as discursive and economic agents, using their communication networks and data transmission resources. The cultural goods that the media oligopolies cross territories, and participate in the formation of consensus under the contemporary logic of flexible capital accumulation and the maintenance of the status quo. Based on the spatial articulation of symbolic, economic and political powers (WEBER, 1999), this text is interested in discussing the geopolitics of the media, according to the postulates developed by the French geographer Philippe Boulanger (2014). The articulation of concepts arising from the geopolitics of media and communication contributes to investigations about power disputes between agents in territories.
\end{abstract}

Keywords: Communication. Geopolitics. Media. Power.

\title{
RESUMEN
}

En la globalización del capital, los oligopolios de la comunicación asumen un papel relevante como agentes discursivos y económicos, utilizando sus redes de comunicación y sus recursos de transmisión de datos. Los bienes culturales que los medios que detienen el oligopolio producen transitan, atraviesan los territorios, participando en la formación de consensos bajo la lógica contemporánea de la acumulación flexible y del mantenimiento del statu quo. Por tratarse de una articulación espacial de poderes simbólicos, económicos y políticos (WEBER, 1999), este artículo se interesa en discutir la geopolítica de los medios de comunicación, a partir de los postulados desarrollados por el geógrafo Philippe Boulanger (2014). La interfaz entre la geopolítica de los medios y la comunicación contribuye a la investigación de las disputas de poder entre los agentes en los territorios.

Palabras clave: Comunicación. Geopolítica. Medios de comunicación. Poder.

\section{INTRODUÇÃO: AINDA A QUESTÃO DO MÉTODO}

De início será preciso nos cercar do cuidado com a acepção de comunicação assumida por este texto: o ato de tornar comum, que guarda em si o entendimento e a ideia de ação possibilitada pela comunhão e definição de acordos que normalizam a vida em comunidade. Tal cuidado é ainda importante pois, como bem anota Muniz Sodré (2014), a 
palavra comunicação remonta a outros sentidos relacionados à ideia de transmissão de mensagens ou de informação, que acabou se impondo sobre o sentido primeiro de "ação comum". Isto se deve, diz o autor, principalmente pelo significado dicionarizado em línguas ocidentais, mas também por ter sido apropriado pelas ciências sociais e humanas como "base para estudos das relações sociais geridas pelas modernas tecnologias da informação e emolduradas no vago quadro teórico do par 'comunicação/informação', que é apenas outro nome para a comunicação moderna, dita também "midiatizada" (SODRÉ, 2014, p. 7-8). Os sentidos implícitos nestas definições, segue o autor, representam uma fonte de ambiguidade e problemas epistemológicos para as aspirações teóricas do campo. Não bastasse a problemática etimológica, a realidade social em movimento se transforma e se impõem ao campo como força que lhe impele a se repensar, construindo novos arcabouços teórico-metodológico. A esse respeito, Octavio Ianni, ao problematizar a tensão entre a tradição e a mudança no campo científico (1992, p. 171), diz:

Se as ciências sociais nascem e desenvolvem-se como formas de autoconsciência científica da realidade social, pode-se imaginar que elas podem ser seriamente desafiadas quando sua realidade já não é mais a mesma. O contraponto de pensamento e pensado, ou de lógico e histórico, pode alterar-se um pouco, ou muito, quando um dos termos modifica-se; e mais ainda quando ele se transfigura.

É nesse cenário epistemológico e histórico-social contemporâneo - globalizado e digital - que se abrem ao campo de estudos da comunicação novos desafios teóricosmetodológicos, uma vez que há, para seguirmos com Ianni, ao mesmo tempo, a alteração das possibilidades do 'sujeito' da reflexão.

A atual complexidade dos sistemas sociais solicita dos pesquisadores abertura para novos desafios, o que nem sempre é confortável para a comunidade acadêmica que representa, nos dizeres de Pierre Bourdieu, um 
(...) espaço social estruturado, um campo de forças - há dominantes e dominados, há relações constantes, permanentes, de desigualdade, que se exercem no interior desse espaço - que é também um campo de lutas para transformar ou conservar este campo de forças. Cada um, no interior desse universo, empenha em sua concorrência com os outros a força (relativa) que detém e que define sua posição no campo e, em consequência, suas estratégias. (BOURDIEU, 2004, p. 57).

Com efeito, o campo científico é um universo com leis sociais próprias - um microcosmo, na definição de Bourdieu. Não obstante e por óbvio, ele está submetido às leis do macrocosmo, ainda que, pensemos com Bourdieu, pode dispor de uma autonomia mais ou menos acentuada. Essa problemática conduz as disciplinas na busca por (...)

(...) saber qual é a natureza das forças externas (...) e sob quais formas se manifestam as resistências que caracterizam a autonomia, isto é, quais são os mecanismos que o microcosmo aciona para se libertar dessas imposições externas e ter condições de reconhecer apenas suas próprias determinações internas (BOURDIEU, 2004, p.19).

No que se refere ao campo científico da comunicação, os debates epistemológicos ainda acalorados mostram que o campo não se apresenta como um campo autônomo, com poder de "refração" das forças externas em consequência de um estruturado arcabouço teórico-metodológico e um objeto definido. Inversamente, trata-se de um campo heterônomo, no qual "problemas exteriores, especialmente políticos, aí se exprimem diretamente" (BOURDIEU,1997, p. 20). Assim, em razão da falta de autonomia, as ciências sociais em geral e muito especialmente as ciências da comunicação sofrem com a debilidade das normas específicas para a constituição de um campo científico relativamente autônomo, que lhe permitiriam, se não se impor ao menos ter algo valioso com que negociar em relação princípios heterônomos externos a que estão sujeitos.

Não obstante parecer um problema, este texto advoga ao que Bourdieu chama de heteronomia dos campos científicos e muito especialmente do campo de estudos da comunicação, a rigor, abre o potencial da ontologia do ser social (RASLAN FILHO, 2013). 
Trata-se a ação humana, socialmente compreendida, de desvelar o desconhecido com as múltiplas formas sociais dispostas para a tarefa. Um arcabouço teórico-metodológico em construção, dessa forma, longe de se constituir uma debilidade, é-lhe condição ontológica, já que se dá como relação social, como disputa em curso sobre um mundo em transformação.

Assim, a porosidade do campo de estudos da comunicação, sua situação fronteiriça, de tensionamento com outros campos, longe de ser um problema, é não apenas, digamos, uma condição epistêmica, como uma espécie de virtù. Todavia, quando se pensa em um campo cujo objeto tem sido quase sempre vinculado ao aparato midiático, a problemática da heteronomia ganha novos contornos e, em vez de alcançar seu estatuto ontológico, tem se estruturado em uma lógica quase sempre mecânica e instrumentalizada. É importante que se diga que essa característica de frivolidade, de prêts-à-penser, para usarmos a expressão desconcertante de Mattelart e Mattleart (1999), do campo da comunicação não lhe retira a condição ontológica; ao contrário: trata-se de entender tal característica como uma disputa, no interior de um campo fronteiriço, entre mundos possíveis, que, se pudermos assim nomear, estaria entre a tecnocracia e a democracia.

Nessa medida, têm razão as movimentações epistêmicas, tal como fez Elisabeth Côrrea (2015) ao discutir a epistemologia da comunicação no contemporâneo digital, para quem, é preciso "buscar uma condição de adaptabilidade de toda estrutura epistemológica que sustenta paradigmas, teorias, modelos e metodologias a este cenário caracterizado como fluido em seus saberes e mutante em suas bases técnicas" (CORRÊA, 2015, p. 8). Com efeito, as transformações técnicas implicam transformações sociais e, nessa medida, transfiguram-se os fenômenos, as condições de sua observação e de seu desvelamento. Por isso, paradigmas e teorias canônicas reivindicadas para a constituição do campo da comunicação nunca são suficientes para compreender a realidade social contemporânea que exige continuamente deslocamentos novos em direção a novas fronteiras que são continuamente tecidas. 


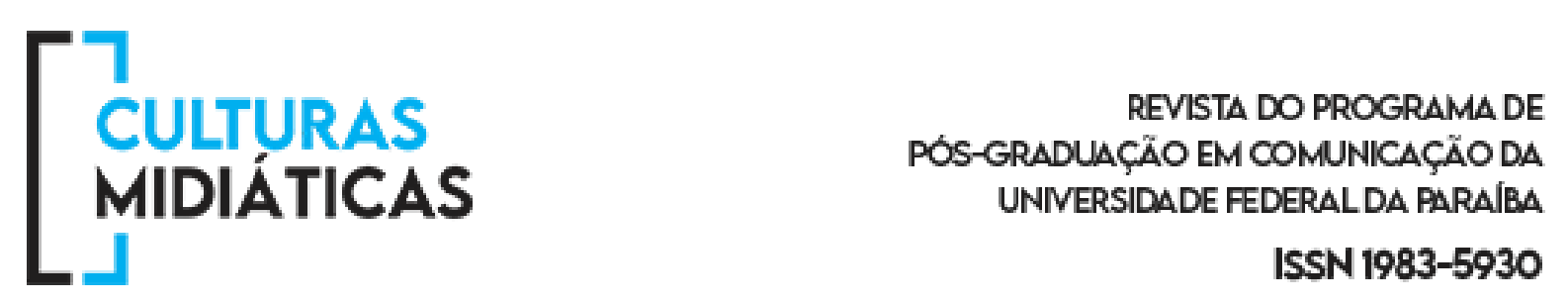

Como campo tenso, transdisciplinar, que atravessa e é atravessado por outros campos de conhecimento, a constituição de métodos para os estudos dos fenômenos que dão forma ao ato de compartilhamento de sentidos ocorre por meio do diálogo entre suas próprias observações e as contribuições de campos diversos: das demais ciências humanas e sociais, das ciências da saúde, da biologia, da engenharia - em uma palavra: da totalidade das disciplinas necessárias para tecer o conhecimento necessário à vida humana. Retomemos Sodré (2014): no tempo presente de economias em redes, mundialização de culturas, ciberativismos, vivenciamos uma movimentação geográfica. $\mathrm{O}$ autor se remete a George W.S. Trow, crítico cultural americano, para discutir a questão comunicacional contemporânea, especialmente o aspecto particular da política e da mídia, apontando para uma movimentação profunda

(...) na 'crosta' da organização simbólica. Disso decorrem transformações de grande monta dos sistemas educacionais, na produção social de subjetividades e na constituição da esfera pública. Mas para nós, sobretudo, uma transformação geográfica no sentido de que essas 'placas', por efeito da compressão temporal do espaço, formam um novo 'continente', o oitavo, feito de bytes, virtual, acima ou abaixo de todos os outros. (SODRÉ, 2014, p. 22).

É nessa medida - e sem perder de vista que tecnologias da informação e comunicação (TIC) são meios de produção sem os quais não há o ato de compartilhamento de sentido necessário para a vida humana - que este texto reivindica a necessidade de compreendê-las, as TIC, em seu campo próprio: a geografia, tanto no sentido dado por Sodré, quanto na necessidade de entender esse novo continente virtual como uma força, a um só tempo, capaz de criar utopias e distopias, cujo poder está em desenhar os espaços concretos onde a vida humana, em sua totalidade, é tecida.

Cumpre, portanto, compreender como essas TICs se condensam e fragmentam espacialmente, como movimentam disputas territoriais relativas aos poderes econômicos, políticos, coercitivos e simbólicos (WEBER, 1999). Esta discussão coloca em interface os 
campos da comunicação e da geopolítica - mais especificamente um seu subcampo: a geopolítica das mídias.

\section{DA GEOPOLÍTICA A GEOPOLÍTICA DAS MÍDIAS}

A geografia política se desenvolveu sobretudo a partir do fim do século XIX na Europa, como disciplina acadêmica, embora, na prática, os estrategistas, os príncipes, bem como os comerciantes tenham-na usado como uma ferramenta de decisão desde os tempos antigos (RAFFESTIN, 1993; BOULANGER, 2014).

O termo geografia política foi fundado em 1897 por Ratzel (1990), geógrafo e etnólogo alemão. ${ }^{1}$ Ratzel tinha como pressuposto a existência de uma estreita relação entre o solo e o Estado, porque compreendia o Estado como o centro de poder. O autor foi responsável pela criação de categorias de análises espaciais que até hoje são utilizadas: centro/ periferia; interior/exterior; crescimento diferencial; vizinhança, entre outras. Segundo os postulados de Ratzel, o Estado é o único núcleo de poder de um território. Nessa medida, Estado e poder se confundem, o que lhe rendeu várias críticas. ${ }^{2}$ Como o Estado representa seu povo, a disputa de poder para o autor não pode ser do Estado contra seu povo, mas entre Estados que defendem seus territórios. O cerne das críticas a tal concepção, todavia, está na constatação de que, no território, há outros conflitos além dos capitaneados pelos Estados.

Rudolf Kjellen, que em 1916 publicou um artigo intitulado "O Estado como forma de vida", analisa o conjunto de forças políticas localizadas como luta entre etnias, ou confrontos entre comunidades. Nessa medida, as rivalidades de poder entre atores sobre um mesmo território ampliam o conceito de geopolítica - e dá a Kjellen o reconhecimento como fundador da disciplina (BOULANGER, 2014; RAFFESTIN, 1993).

\footnotetext{
${ }^{1}$ Ratzel também é reconhecido como um dos fundadores da geografia humana. Ver Ratzel 1990; Raffestin, 2003.

${ }^{2}$ Sobre as questões epistemológicas da geopolítica, ver RAFFESTIN, 1993.
} 


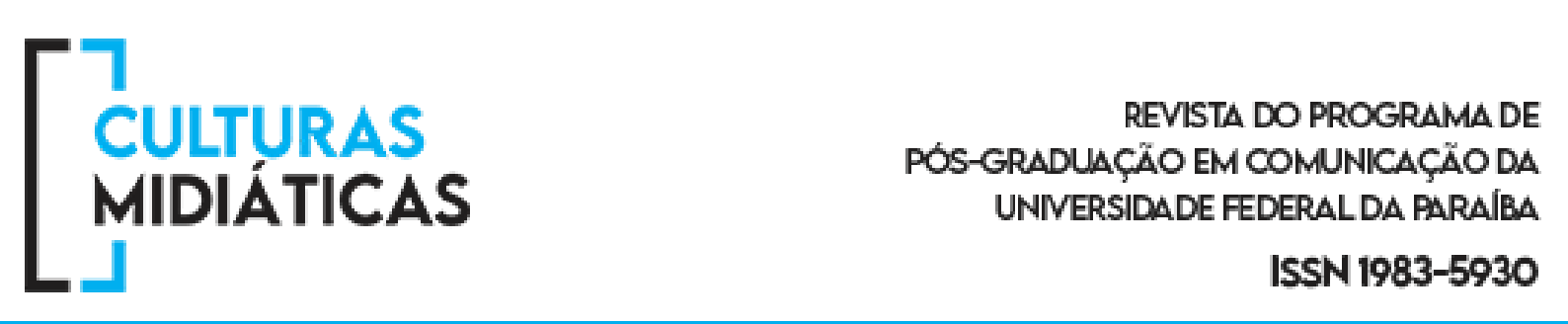

Fundadores a parte, a noção de geopolítica foi concebida como um estudo estratégico apropriado, sobretudo, pelo poder militar, os príncipes e os comerciantes. Suas concepções fundantes, como uma geografia de guerra, foram alguns dos motivos que a marginalizaram dentro dos estudos da geografia humana depois da Segunda Guerra Mundial, com exceção aos estudos estadunidenses (RAFFESTIN,1993).

Tem-se assistido ao seu retorno, desde o final da Guerra Fria, todavia, quando se redescobre uma nova geopolítica ligada à globalização das trocas econômicas, o surgimento de novas tensões e ameaças, a emergência de novas potências, que se deveram, dentre outros fatores, às transformações das tecnologias de informação e comunicação. Nessa medida, desde os anos 1980, a geopolítica passou a ser novamente objeto de atenção de estudos no campo da geografia. O que, para Boulanger, em seu "Géopolitique dés média: acteurs, rivalités e conflits" (2014), se deve em grande parte aos esforços dos especialistas que se debruçam sobre o campo, mas também à opinião pública que quer compreender as mutações do desenvolvimento mundial cada vez mais complexo.

Para Boulanger a geopolítica diz respeito ao estudo das rivalidades de poderes, a luta de influência entre diferentes atores em um determinado território, em diferentes escalas geográficas. A partir dessa definição, Boulanger (2014, p. 37) apresenta a geopolítica das mídias como "um estudo das rivalidades de poder entre os atores midiáticos, a representação da luta de influência pelas mídias, do discurso das mídias como revelação da mutação geopolítica em curso" (Tradução livre) . ${ }^{3}$

Parte-se da premissa de que as mídias constituem, efetivamente, um fator de alterações consideráveis da geopolítica mundial. Boulanger destaca alguns dos elementos que aparecem no tempo presente e participam dessa transformação:

(...) a inserção das redes de fibra ótica submarinas, o poder dos grandes grupos de mídia global, a ascensão dos conflitos cibernéticos, a

\footnotetext{
3. "l'ètude des rivalités de pouvoirs entre les acteurs médiatiques, de la representation de ces lutes d'influence par les médias, du discours des médias comme revélation des mutation géopolitiques en cours" (BOULANGER, 2014, p. 37).
} 
competição entre cidadãos e os meios de comunicação, o surgimento de cidades inteligentes, guerras e batalhas de significado por meio das mídias, os usos de redes sociais nos movimentos de contestação popular aparecem como elementos entre outros. (BOULANGER, 2014, p. 8, tradução livre). ${ }^{4}$

Paralelamente, participam da elaboração de uma outra aproximação da geopolítica das mídias os aspectos relativos à produção dos conteúdos comunicativos que dizem respeito ao tratamento midiático sobre temas como as crises e os conflitos. Essa aproximação analisa os discursos, as imagens, os suportes midiáticos, utilizados com o objetivo de compreender as questões que constituem as estratégias territoriais dos atores junto à opinião pública e ao Estado (BOULANGER, 2014).

Em suma, a geopolítica das mídias representa uma perspectiva interdisciplinar entre a geografia, a política, os estudos de mídia e da comunicação. Consiste em estudar as rivalidades de poderes sobre um território, as rivalidades entre os atores midiáticos e de representação dessas lutas de influência pelo acesso e apropriação do aparato técnico midiático.

As fontes e dispositivos de informação são, ambas, componentes de processos de formação de opinião e assim - se se pensa em poder simbólico e a propriedade dos meios de produção simbólicos - trata-se de um poder constitutivo da opinião circulante. Nesse sentido, Boulanger (2014) destaca que a geopolítica é um campo privilegiado para compreender as estratégias de controle, as tensões e as rivalidades entre os atores, o que se dá por meio de um aporte teórico-metodológico próprio, embora tenso, constituído por critérios e categorias de conceitos fundamentais.

\section{CRITÉRIOS E CATEGORIAS DE CONCEITOS FUNDAMENTAIS}

\footnotetext{
4 "la mise em place des réseaux de fibre optique sousmarins, la puissance des grands groupes du Global media, l'essor des cyberconflits, les concurrences entre les cités des médias, l'émergence des smart cities, les guerres du sens et les batailles de la perception à travers les medias, l'utilisation des réseaux sociaux dans les mouvements de contestations populaires apparaissente comme des éléments parmi d'autres" (BOULANGER, 2014, p. 8). .
} 
São quatro os critérios que sustentam a geopolítica das mídias. O primeiro trata da infraestrutura das mídias e permite compreender a evolução de novas técnicas em diferentes épocas e mensurar seus impactos sobre as atividades sociais. Produção midiática é o segundo critério de observação e diz respeito ao estudo relativo ao monopólio e a concentração da indústria de produção midiática. Tal estudo, em razão de sua amplitude, diz Boulanger (2014), não pode ser inventariado ou cartografado. O critério do consumo, é o terceiro critério e diz respeito aos estudos que se interessam por analisar os diferentes grupos mundiais da publicidade, suas estratégias, mensagens e interesses. Para Boulanger (2014, p. 44), esse critério "permite não somente abordar a dinâmica de influência em diferentes escalas geográficas, mas também aproximar uma geografia social e cultural dos comportamentos, dos gostos, das hierarquias sociais e dos usos" (tradução livre). ${ }^{5}$ Nessa perspectiva, a dinâmica geopolítica se interessa, sobretudo, pelas estratégias de influência dos principais agentes de pressão sobre a opinião pública.

Por fim, o critério dos fluxos de informação trata da extensão das telecomunicações e dos estudos numéricos. Os estudos dos fluxos de informação permitem compreender as estratégias de influência dos atores. Boulanger apresenta como exemplo a análise geográfica sobre a distribuição dos cabos submarinos e dos fluxos da internet no mundo. Essas análises revelam, segundo o autor, grandes controladores localizados, sobretudo na América do Norte, Europa e Ásia (Japão). Revelam também, a desigualdade de acesso a novas tecnologias existente, por exemplo, entre os hemisférios Norte e Sul.

A partir desses critérios, a geopolítica das mídias definiu três categorias de conceitos fundamentais e permanentes. A primeira é denominada estudos da informação e da comunicação, e foram concebidos a partir de aproximações com as telecomunicações. Nessa categoria, supõem-se um suporte e um conteúdo; a transformação e a representação de uma informação; a comutação e a conexão. Trata-se das trocas informacionais de

\footnotetext{
5 "Permet non seulement d'aborder les dynamiques d'influence à différentes échelles géographiques mais aussi d'approcher une geographie sociale et culturalle des comportements, des goûts, des hiérachies sociales e des usages" (BOULANGER, 2014, p. 44).
} 
natureza distinta, econômicas ou financeiras, políticas ou militares, e trabalham com várias categorias de conceitos: nós e ramos; a difusão e a conexão em relação aos lugares nos quais se encontram; a estrutura da rede; sua acessibilidade e seu ritmo de desenvolvimento.

Centro e periferia é a segunda categoria de conceitos fundamentais. Trata-se de conceitos tradicionais nas reflexões da geografia, como já se expôs anteriormente. Na geopolítica das mídias, essa categoria permite mensurar o grau de integração midiática espacial; compreender as matrizes do território pela cobertura midiática; a interconexões de subespaços no interior de um território e, por fim, a diversidade de atores sobre o território. Para Boulanger (2014, p. 51), a relação entre o centro e a periferia revela dinâmicas geopolíticas "ligadas ao jogo de atores (indivíduos, operadores, Estado, instituições supranacionais como a união internacional de telecomunicações) e as capacidades tecnológicas que emitem em direção aos espaços colocados sob suas influências"

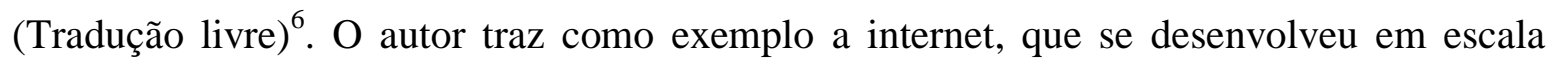
planetária, mas que se caracteriza por uma forte centralidade de poder que parte dos Estados Unidos - notadamente dos hubs de Internet da costa Oeste e Leste, responsáveis por 2/3 dos computadores conectados no mundo, ao lado da Europa e do Japão. Esta tríade se coloca em contraposição as periferias "pseudoconectadas" - cuja conexão cobre um território muito pontual e estratégico, apenas para servir de aporte geopolítico das redes globais.

Por fim, o terceiro conceito consiste no domínio das representações geopolíticas. Designa, de maneira geral, a estrutura cognitiva do tratamento midiático, a conceitualização dos fatos evidenciados. As análises partem dos suportes midiáticos utilizados, das imagens, dos discursos com o objetivo de compreender os jogos discursivos que constituem os territórios e as estratégias territoriais dos atores ao lado da opinião pública. Por exemplo, o tratamento midiático sobre temas relativos a energia nuclear que tratam de acordos

\footnotetext{
6 “(...) liées au jeu des acteurs (indiidus, oérateurs, États, institutions supranationales comme 1'Union internationale des télécommunications) et aux capacités technologiques qui émettent vers des espaces à placer sous influence" (BOULANGER, 2014, p. 51)
} 
internacionais. Trata-se de uma operação de formação da opinião pública a favor ou contra os programas nucleares e revelam, por seu discurso, jogos de interesses de um país contra o outro. É nessa medida que podem-se observar, nos pressupostos dos estudos da geopolítica das mídias, também as questões relativas ao tempo histórico: ações e processos de curta, média e longa duração, que visam resultados práticos imediatos, criação de expectativas ou operações de memória para as transformações do passado.

\section{CONSIDERAÇÕES FINAIS}

No tempo histórico presente, os dispositivos técnicos, os signos e os discursos são pressupostos de uma nova forma de socialização. Eles formam um ecossistema no qual a comunicação se apresenta como um modo geral de organização, assumindo seu sentido de partilha, de ação comunicada. Nas palavras de Sodré,

(...) instalada como um mundo de sistemas interligados de produção, circulação e consumo, a nova ordem sociotécnica fixa-se no ponto histórico do aqui e agora, não como índice de um novo modo de produção econômico, mas como a continuidade, com dominância financeira e tecnológica, da mercantilização iniciada pelo capitalismo no início da Modernidade ocidental. No necessário rearranjo de pessoas e coisas, a comunicação revela-se como principal forma de organização. (SODRÉ, 2014, p. 16).

Nessa perspectiva, as tecnologias de informação e comunicação que atravessam as relações sociais cotidianas ampliam o poder de corporações midiáticas, que assumem uma dupla face: ao mesmo tempo se projetam como agentes discursivos, com uma proposta ideológica em torno da acumulação flexível de capital; e, por outro lado, como agentes econômicos proeminentes nos mercados mundiais. Mas não são apenas as corporações midiáticas que se projetam - outros agentes se empoderam pela rede, como se vê no ciberativismos. Esse cenário indica a dimensão da disputa entre diferentes atores pela 
capacidade de produzir, distribuir e fazer circular material sígnico, em uma nova "guerra dos deuses" pela produção de sentido compartilhado.

Sobre os estudos das ciências da comunicação, como ressalta Sodré, interessa compreender não necessariamente os dispositivos per se, mas como se dão os usos sociotécnicos dessas tecnologias no cotidiano, na realidade dos sujeitos, nas disputas simbólicas que travam em territórios onde os tecem as relações e práticas comunicativas. Trata-se, portanto, de compreender que as redes que forjam o globalismo, fortemente sustentado nas tecnologias de informação e comunicação, não dispensam a distribuição e alcance da estrutura física de tais redes pelos territórios, o que, em uma palavra, implica assumir que os fenômenos contemporâneos, as tensões, fricções e deslocamentos que ocorrem na crosta dos continentes e ilhas de signos são profundamente configurados pelos amálgamas de interesses geopolíticos.

Neste texto, buscamos apresentar a geopolítica das mídias, seus critérios e categorias de conceitos fundamentais, uma área de pesquisa que objetiva compreender as rivalidades de poder exercido pelas organizações midiáticas sobre um território, seja qual for o reflexo das transformações geopolíticas, sejam quais forem os atores. Essa apresentação se coloca como perspectiva de diálogo e contribuição para as pesquisas em comunicação que transitam por temas geográficos e políticos, sobre disputas de poder entre agentes nos territórios. Trata-se de um tema pouco discutido que solicita a produção de pesquisas e publicações científicas - um diálogo ainda em construção de um território ainda em formação.

\section{REFERÊNCIAS}

BOULANGER, Philippe. Géopolitique des médias: acteurs, rivalités et conflits. Paris: Armand Colin, 2014

BOURDIEU, Pierre. Os usos sociais da ciência: por uma sociologia clínica do campo científico. São Paulo: Edidora UNESP, 2004. 


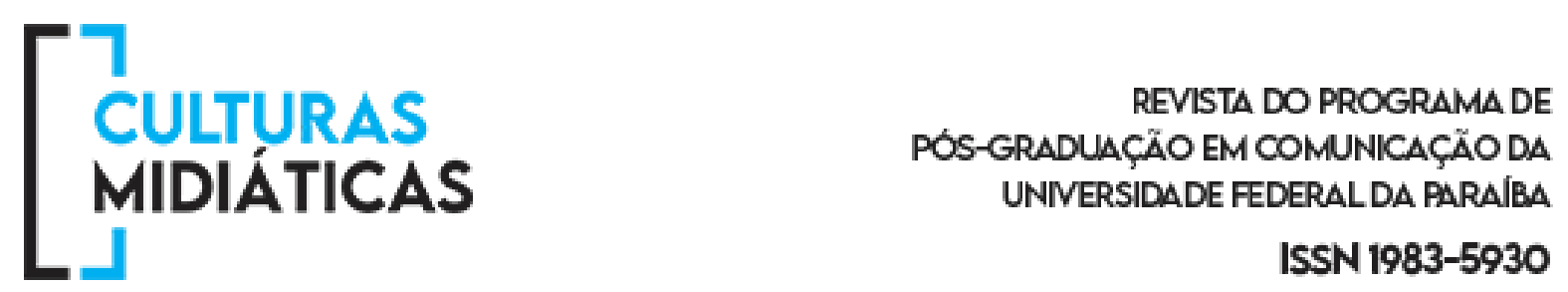

CÔRREA, Elisabeth Saad. Centralidade, transversalidade e resiliência: reflexões sobre as três condições da contemporaneidade digital e a epistemologia da Comunicação. In: Divisão Temática Ibercom Epistemologia, Teoria e Metodologia da Comunicação no XIV Congresso Internacional IBERCOM, na Universidade de São Paulo, de 29 de março a 02 de abril de 2015.

IANNI, Octavio. A sociedade global. Rio de Janeiro: Civilização Brasileira, 1992.

MATTELART, Armand; MATTELART, Michele. História das teorias da comunicação. São Paulo: Loyola, 1999.

MORAES, D. O capital da mídia na lógica da globalização. In: (Org). Por uma outra comunicação: mídia, mundialização cultural e poder. Rio de Janeiro/São Paulo: Editora Record, 2005.

RAFFESTIN, C. Por uma geografia do poder. São Paulo: Editora Ática, 1993.

RASLAN FILHO, Gilson Soares. Em busca de uma ontologia do processo comunicativo: ou encruzilhadas de um campo científico. In: Revista INTEXTO. No 29, 2013. Porto Alegre: UFRGS, 2013. Disponível em: https://seer.ufrgs.br/intexto/article/view/41591 Acesso em: 27 de julho de 2020.

RATZEL, F. Coleção Grandes cientistas sociais: Geografia. São Paulo: Editora Ática, 1990.

SODRÉ, Muniz. A ciência do Comum: notas para o método comunicacional. Petrópolis, RJ: Vozes, 2014.

WEBER, M. Economia e sociedade: fundamentos da sociologia compreensiva / Max Weber; tradução de Regis Barbosa e Karen Elsabe Barbosa; Revisão técnica de Gabriel Cohn - Brasília, DF: Editora Universidade de Brasília: São Paulo: Imprensa Oficial do Estado de São Paulo, 1999. 